\title{
Research on the Development of Sports Tourism Resources from the Perspective of Industrial Convergence
}

\author{
Feng Mu \\ Weinan Normal University, Weinan, 714000, China
}

Keywords: Industrial Integration, Sports Tourism, Resources Development

\begin{abstract}
The development of tourism urges consumers to enjoy more and more high-level experiences in tourism projects, and the combination of sports and tourism projects has become an inevitable trend. The existing large-scale sports events such as the World Cup, the Olympic Games and the Asian Games as well as the mass-based experiential events are the direct embodiment of the integration of the sports and tourism industries. At present, China's sports tourism industry is still in its infancy. Based on the analysis of industrial integration, the development of sports tourism resources can promote the rapid development of sports tourism industry and enhance the comprehensive competitiveness of the industry.
\end{abstract}

\section{The Concept of Sports Tourism}

At present, the definition of sports tourism is mainly based on the perspective of tourism, such as product, space and motivation, but not exactly defined from the essential attributes of sports tourism. Compared with the traditional tourism industry, the core of the concept of sports tourism lies in its "sports" attribute. It develops the market with the tourism industry and provides the core resources with the sports. Therefore, the sports tourism has the double character in the industry attribute. It not only has the characteristics of tourism industry, but also is an important part of the sports industry. In essence, it belongs to the category of sports industry and is a direct manifestation of the diversified functions of the sports industry. Therefore, "National Sports Industry Statistical Classification" Activities "belong to a sub-project of" Other Sports-Related Services "in the Sports Industry. Based on the economics of industrial integration, the definition of sports tourism is the new type of service industry in which the sports industry and tourism industry penetrate each other through the industrial value chain, with the sports ontology resource as the core and the tourism service elements as the carrier. The sports ontology resource including sports fitness leisure projects, sports events, large stadiums, which combines the characteristics of the sports industry and tourism industry characteristics.

\section{The Basic Conditions for the Integration of Sports and Tourism Industry}

Analyzing the essence of sports and tourism, we can see that sport is a man-centered practical activity, and the ultimate goal is to transform the human body through physical activity. The ultimate goal of human beings is to transform people by themselves, and both of them belong to Human self-design, self-development, and both are important components of other activities in human mental activity. In the long course of development of human civilization, body entertainment not only affects people's daily life, but also exerts more or less influence on human's cultural and spiritual development. Many entertainment activities involve sports, especially in the highly developed modern society. The role of sports in maintaining and promoting the physical and mental health of human beings is becoming more and more prominent. The main purpose of tourism activities is also the pursuit of spiritual pleasure and physical and mental health, so as to obtain satisfaction and happiness, we can see that the nature of sports and tourism have the same nature, the two can be combined together to promote each other and seek common development.

The essence of sports is a serious game. The interesting attributes of the game make people have a fun activity experience while participating in the game. The body game is universal and 
entertaining. The ultimate goal of body games is to show a unique form of culture in the general sense of physical activity. Similarly, tourism is also an experiential physical practice. Although it is not a category of games, people have mental pleasure in the practice of tourism, and tourism has outstanding regional characteristics. People from familiar places another strange place, the process itself has a strong entertainment. It can be seen from this that both sports and tourism activities aim at meeting the spiritual needs of the people, and people experience the same feeling during the activities.

Both sports and tourism are comprehensive social phenomena. Both involve a wide range of fields. Both the sports industry and the tourism industry, while developing themselves will also extend to other industries. Therefore, the boundaries of the sports and tourism industries are rather vague. Sports industry itself has its own particularity, that is, the commonality of assets. This versatility can produce greater market value without sacrificing too much industrial value to complement and integrate with other industrial resources. The tourism industry and the sports industry can exchange and complement each other in aspects of assets, resources, markets and technologies so as to maximize the value of assets and resources. Of course, the organic integration of the sports and tourism industry is only a vague boundary and can not be completed, and the two have certain relevance. The sports industry can not only organize sports events, but also promote the development of other peripheral industries, such as clothing and footwear, exercise equipment, etc. The same tourism industry relies on tourism resources to attract tourists. However, the tourist resources include not only historical sites and natural scenery but also various types Folk activities and so on.

\section{The Development of Sports Tourism Resources from the Perspective of Industrial Integration Strategy}

The development of sports tourism resources must determine its development orientation, whether it is natural resources or human resources, can be divided into real and potential resources tourism resources, the reality of tourism resources is the resource project has matured, not only for tourists themselves have a strong attraction Resources, and is receiving a large number of tourists resources; potential resources refers to not yet known to outsiders, traffic and other conditions are not yet ready for the reception, but the resource itself has some characteristics that attract tourists. Potential tourism resources must be consciously man-made development in order to create a better tourism environment, and thus become a real tourist resource that can create economic value. This shows that the development of sports tourism resources includes not only the current resources, but also other potential resources. It should be noted that tourism resources objectively have a certain life cycle. Even relatively mature and realistic resources should be regenerated according to their actual conditions so as to optimize the allocation of tourism resources and enhance the attractiveness of the project. In the process of developing sports tourism resources, the types and distribution characteristics of resources, the value of actual development and development and the potential value of development are all the basic conditions for the development of sports tourism. When developing sports tourism resources, they must be clearly positioned to ensure the development of sports tourism resources in a probable, trendy value range.

The development of sports tourism resources to follow the following principles: First, the economic principle. The development of sports tourism resources must be based on the actual situation of local social and economic development and avoid the blindness in the process of resource development. If the cost of developing sports tourism resources is higher than the benefits it can bring, it should be carefully considered. The development of sports tourism resources should highlight its own characteristics, continuous innovation and continuous optimization in order to ensure its comprehensive competitiveness in the tourism industry market and attract more tourists. The development of sports tourism resources should actively excavate and organize regional special resources to realize the harmonious unity of nationality and locality, primitiveness and nature, traditionality and modernity, and to show visitors the unique charm of the region. The ultimate goal of sports tourism is to make tourists enjoy physical and mental pleasure in participating in sports 
and tourism activities. Therefore, the necessary safety and security measures are the important conditions to ensure tourists get a good experience. In the development of sports tourism products and projects should be based on the theory of sports physiology, good protective measures to ensure that tourists participate in sports tourism activities both to obtain spiritual satisfaction, but also to ensure their physical safety. However, to realize the sustainable development of sports tourism resources, we must follow the principle of greenness, integrate the development of resources with the protection of resources, and the development of resources must not be at the expense of ecological environment in order to achieve the synergistic development of economic benefits and ecological benefits of sports tourism.

More and more personalized tourist needs, diversified, only the development of a wide range of sports tourism products to better meet the needs of tourists. In terms of cultivating sports tourism products, all regions should rely on their own resource characteristics to combine nature, sports and humanities organically to speed up the construction of public sports facilities in the region; and to develop more specialized sports programs in specific regions such as rivers and lakes can develop water sports, snow and ice can develop snow sports and so on. Build a comprehensive and comprehensive sports amusement park, design new sports and amusement projects, set up a sports theme park from the perspective of macroeconomic strategy, draw lessons from the internationalized mode of operation, and design the overall plan of events and activities. Second, establish a sports tourism brand image. All regions should change from a single resource element competition to a brand effect competition to better adapt to the increasingly competitive sports tourism market. The development of sports tourism industry should establish brand awareness, clear brand development goals, adopt a scientific and effective brand promotion strategy, give full play to advantages of various resource elements such as knowledge, manpower and capital, and create a distinctive and advanced regional sports tourism brand. Finally, to further expand the sports tourism consumer market. All localities should step up publicity and promotion of local sports tourism projects and formulate appropriate promotion methods so that sports tourism will be integrated into the life of consumers with a healthy lifestyle. The use of television, radio, the Internet, newspapers and other mass media, publicity and display their own unique sports tourism industry, so that people gradually understand the emerging tourism products, so that more potential demand.

\section{Conclusion}

In short, the development of sports tourism resources in China is still relatively low, and there are significant geographical and cultural differences in different regions. Therefore, the development of sports tourism resources has broad market prospects. However, in the process of development, it should be noted that the development of resources of traditional sports can not be neglected in planning new sports tourism projects to ensure the popularity of tourism products. Further improve the profit-making system of sports tourism projects, improve the specialization of the sports training market, strengthen publicity and policy support for recreational and sports tourism resources, and improve the scientific planning and design of sports tourism and sports content. In addition, we must further explore sports tourism Industry rules of development, summed up a set of operable, targeted talent training system, in order to transport the development of sports tourism industry delivery of more high-quality talent. Of course, the development of sports tourism resources is a long-term, systematic project. In the follow-up, we must strengthen our research. We must not only develop the renewable resources of real resources but also fully tap the potential resources so as to continuously enrich the product categories in the sports tourism market so as to achieve the sustainable development of sports tourism industry.

\section{References}

[1] Han Lu'an, Cui Jian, peace, etc. The role of sports tourism in national economy and social development [J]. Journal of Tianjin Institute of Physical Education, 2017,15 (2): 42-44. 
[2] Xu Hong, Fan Qing. A Study on Obstacles in the Integration of China's Tourism Industry and Strategies for Promoting their Competitiveness [J]. Tourism Science, 2015, 22 (4): 1-5.

[3] GUO Xun, Wu Zhong-Jun. Classical Barriers to Governmental Cooperation in Regional Tourism Development and Countermeasures [J]. Human Geography, 2016, (1): 106- 108

[4] Li Q. Internal mechanism and external motivation of integration and development of sports industry and related industries [J]. Journal of Beijing Sport University, 2013,36 (11): 20-24.

[5] Wang Yan, Liu Jinsheng. Sports Industry Integration and Industrial Development - A New Perspective of Sports Industry Development in China [J] Journal of Chengdu Physical Education Institute, 2015,35 (7): 7-10.

[6] Vigorously Develop Sports Tourism and Promote the Coordinated Development of Sports Industry and Sports Industry - Keynote Speech at China Sport Tourism Development Forum 2012 [J]. P. Culture, 2013 (2): 1-5.

[7] Chang Liying, Li Yongqiang. Analysis on Value Chain Integration of Sports Industry in China and Its Strategy [J]. Journal of Beijing Sport University, 2017,34 (4): 35-39. 